\title{
X-Ray Crystallographic Approach to the Design of Phenolic Schiff Base Reagents for the Mutual Separation of Lanthanoids
}

\author{
Koji Kubono, ${ }^{* \dagger}$ Naoki Hirayama,** Hisao KoKusen,*** and Kunihiko YoKoI* \\ *Division of Natural Science, Osaka Kyoiku University, Kashiwara, Osaka 582-8582, Japan \\ **Department of Chemistry, Faculty of Science, Kanazawa University, Kanazawa 920-1192, Japan \\ ***Department of Chemistry, Faculty of Education, Tokyo Gakugei University, \\ Koganei, Tokyo 184-8501, Japan
}

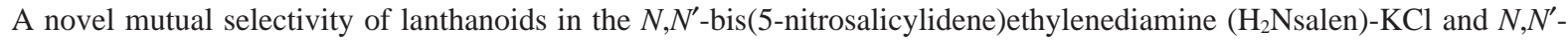
bis(5-nitrosalicylidene)-o-phenylenediamine $\left(\mathrm{H}_{2} \mathrm{Nsaloph}\right)-\mathrm{KCl}$ extraction systems was evaluated by the $\mathrm{X}$-ray analysis of similar model complexes for extracted species. Cerium(IV) complexes with $N, N^{\prime}$-bis(5-chlorosalicylidene)ethylenediamine $\quad\left(\mathrm{H}_{2}\right.$ Clsalen), $\quad N, N^{\prime}$-bis(salicylidene)-o-phenylenediamine $\quad\left(\mathrm{H}_{2} \mathrm{saloph}\right) \quad$ and $\quad N, N^{\prime}$-bis(3,5dibromosalicylidene)-o-phenylenediamine $\left(\mathrm{H}_{2} \mathrm{Br}_{2} \mathrm{saloph}\right)$ were selected as the models. The result of the $\mathrm{X}$-ray analysis suggested that $\left[\mathrm{Ln}(\mathrm{III})(\mathrm{Nsalen})_{2}\right]^{-}$and $\left[\mathrm{Ln}(\mathrm{III})(\mathrm{Nsaloph})_{2}\right]^{-}$are meridional type (two ligands are oriented perpendicular to each other) and sandwich type (two ligands are oriented parallel to each other), respectively. It was suggested that the selectivity of the meridional structure is superior to that of the sandwich structure in these extraction systems.
\end{abstract}

(Received September 19, 2000; Accepted October 4, 2000)

Lanthanoids have been utilized for magnetic and luminous materials, catalysts, or shift reagents, etc. ${ }^{1}$ The mutual separation of lanthanoids in high purity, however, is very difficult owing to their remarkable chemical similarities. The only clue to their separation is a slight difference of their ion radii. $^{2-4}$ Solvent extraction using a metal-complexing reagent is one of best choices as the separation method, ${ }^{5,6}$ and reagents having novel ion-size recognition ability have been desired. Several novel lanthanoids extraction systems have been investigated. ${ }^{7-9}$

Recently, we reported that quadridentate phenolic Schiff bases containing a nitro group, $N, N^{\prime}$-bis(5-nitrosalicylidene)ethylenediamine $\left(\mathrm{H}_{2} \mathrm{Nsalen}\right)$ and $N, N^{\prime}$-bis(5-nitrosalicylidene)$o$-phenylenediamine $\left(\mathrm{H}_{2} \mathrm{~N}\right.$ saloph), can act as an effective extractant for the mutual separation of $\mathrm{Ln}^{3+}$ under the coexistence of a suitable counter cation. ${ }^{9}$ Furthermore, the mutual selectivity of lanthanoids on $\mathrm{H}_{2} \mathrm{Nsalen}$ was higher than that on $\mathrm{H}_{2} \mathrm{Nsaloph}$. The difference in the selectivity between these systems seems to result from the structure of the ligands or their complexes. We have aimed to design and construct a superior mutual separation system between lanthanoids. It is essential to evaluate the difference in the selectivity of the above two extraction systems from a structural viewpoint by $\mathrm{X}$ ray crystallography. We tried to determine the structure of $\mathrm{M}^{+}\left[\mathrm{Ln}(\mathrm{III})(\mathrm{Nsalen})_{2}\right]^{-}$or $\mathrm{M}^{+}\left[\mathrm{Ln}(\mathrm{III})(\mathrm{Nsaloph})_{2}\right]^{-}$(for example, $\mathrm{M}^{+}=\mathrm{K}^{+}, \mathrm{Et}_{4} \mathrm{~N}^{+}$, etc.) by single-crystal X-ray diffraction. However, the ion-pair Ln-complexes cannot be crystallized, but were merely precipitated, possibly owing to the existence of a nitro group in the ligands, or the difficulty in selecting a counter cation suitable for crystallization. Alternatively, the ligands containing an electron-attracting halogen group, $\mathrm{H}_{2}$ Clsalen ( $N, N^{\prime}$-bis(5-chlorosalicylidene)ethylenediamine) and $\mathrm{H}_{2} \mathrm{Br}_{2} \mathrm{Saloph}$ ( $N, N^{\prime}$-bis(3,5-dibromosalicylidene)-o-phenylenediamine),

† To whom correspondence should be addressed. non-substituted ligands, $\mathrm{H}_{2}$ salen $\left(N, N^{\prime}\right.$-bis(salicylidene)ethylenediamine) and $\mathrm{H}_{2}$ saloph ( $N, N^{\prime}$-bis(salicylidene)- $o$ phenylenediamine), were selected as models of $\mathrm{H}_{2} \mathrm{Nsalen}$ and $\mathrm{H}_{2} \mathrm{Nsaloph}$, respectively. $\mathrm{Ce}^{4+}$ was selected as a central metal ion, because it can easily form a 1:2 uncharged crystalline complex with $\mathrm{H}_{2} \mathrm{Cl}$ salen or $\mathrm{H}_{2} \mathrm{Br}_{2} \mathrm{Saloph}$, rather than $\mathrm{Ln}^{3+}$, and its ion size is almost the same as that of $\mathrm{Lu}^{3+}$, which is the smallest cation in $\mathrm{Ln}^{3+}$. The molecular structure of lanthanoid complexes, e.g. coordination number $(\mathrm{CN})$, seems to be influenced mainly by the size of the central lanthanoid ions, rather than their charge. Actually, the typical $\mathrm{CN}$ of the smaller $\mathrm{Ln}^{3+}$ (heavy lanthanoid ions) and $\mathrm{Ce}^{4+}$ is eight, and it is considered that $\mathrm{Ce}^{4+}$ complexes with $\mathrm{H}_{2}$ Clsalen or $\mathrm{H}_{2} \mathrm{Br}_{2}$ Saloph can be used as a model of $\left[\mathrm{Ln}(\mathrm{III})(\mathrm{Nsalen})_{2}\right]^{-}$or $[\mathrm{Ln}(\mathrm{III})$ $\left.(\text { Nsaloph })_{2}\right]^{-}(\mathrm{Ln}=$ small trivalent lanthanoids $)$.

Herein, we report on the result of an X-ray structural analysis of lanthanoid complexes with halogen-substituted $\mathrm{H}_{2}$ salen or $\mathrm{H}_{2}$ saloph as model complexes, whose structure is presumed to be the same as that of extracted species in the mentioned $\mathrm{Ln}^{3+}$ $\mathrm{H}_{2} \mathrm{Nsalen}$ or $\mathrm{Ln}^{3+}-\mathrm{H}_{2} \mathrm{Nsaloph}$ system, and evaluate the difference of the selectivity of the above two extraction systems, and mention the design of a superior mutual separation reagent.

\section{Experimental}

\section{Reagents}

The ligands $\mathrm{H}_{2}$ Clsalen and $\mathrm{H}_{2} \mathrm{Br}_{2}$ saloph (Fig. 1) were synthesized from 5-chlorosalicylaldehyde and ethylendiamine, and 3,5-dibromosalicylaldehyde and o-phenylenediamine, respectively, according to literature methods. ${ }^{10}$

\section{Preparation of the model complexes}

$\mathrm{Ce}^{4+}$ complexes with $\mathrm{H}_{2}$ Clsalen and $\mathrm{H}_{2} \mathrm{Br}_{2}$ saloph were prepared by a modifying a literature method. ${ }^{11}$ 


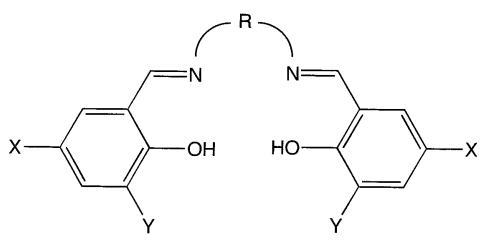

$\begin{array}{llll} & \mathrm{R} & \mathrm{X} & \mathrm{Y} \\ \mathrm{H}_{2} \text { salen } & -\mathrm{CH}_{2} \mathrm{CH}_{2}- & -\mathrm{H} & -\mathrm{H} \\ \mathrm{H}_{2} \text { saloph } & o-\mathrm{C}_{6} \mathrm{H}_{4} & \mathrm{H} & \mathrm{H} \\ \mathrm{H}_{2} \text { Nsalen } & \mathrm{CH}_{2} \mathrm{CH}_{2} & \mathrm{NO}_{2} & \mathrm{H} \\ \mathrm{H}_{2} \text { Nsaloph } & o-\mathrm{C}_{6} \mathrm{H}_{4} & \mathrm{NO}_{2} & \mathrm{H} \\ \mathrm{H}_{2} \text { Clsalen } & \mathrm{CH}_{2} \mathrm{CH}_{2} & \mathrm{Cl} & \mathrm{H} \\ \mathrm{H}_{2} \text { Clsaloph } & o-\mathrm{C}_{6} \mathrm{H}_{4} & \mathrm{Cl} & \mathrm{H} \\ \mathrm{H}_{2} \text { Brsaloph } & -\mathrm{C}_{6} \mathrm{H}_{4} & \mathrm{Br} & \mathrm{H} \\ \mathrm{H}_{2} \text { Br } & & & \\ \end{array}$

Fig. 1 Structure of Schiff base ligands.

Table 1 Crystallographic data of complexes $\mathbf{1}$ and $\mathbf{2}$

\begin{tabular}{lll}
\hline & $\mathrm{Ce}(\text { Clsalen })_{2}(\mathbf{1})$ & $\mathrm{Ce}\left(\mathrm{Br}_{2} \mathrm{saloph}_{2}(\mathbf{2})\right.$ \\
\hline Formula & $\mathrm{C}_{32} \mathrm{H}_{24} \mathrm{CeCl}_{4} \mathrm{~N}_{4} \mathrm{O}_{4}$ & $\mathrm{C}_{40} \mathrm{H}_{20} \mathrm{Br}_{8} \mathrm{CeN}_{4} \mathrm{O}_{4}$ \\
Formula weight & 810.50 & 1139.83 \\
Crystal size $(\mathrm{mm})$ & $0.25 \times 0.30 \times 0.35$ & $0.35 \times 0.10 \times 0.10$ \\
Crystal system & orthorhombic & triclinic \\
Space group & $P 2_{1} 2_{1} 2_{1}$ & $P \overline{1}$ \\
$a(\AA)$ & $15.47(1)$ & $12.89(1)$ \\
$b(\AA)$ & $16.79(1)$ & $15.74(2)$ \\
$c(\AA)$ & $13.38(3)$ & $12.14(4)$ \\
$\alpha\left(^{\circ}\right)$ & 90 & $100.2(1)$ \\
$\beta\left({ }^{\circ}\right)$ & 90 & $99.4(1)$ \\
$\gamma\left({ }^{\circ}\right)$ & 90 & $82.99(8)$ \\
$V\left(\AA^{3}\right)$ & $3475(7)$ & $2381(7)$ \\
$Z$ & 4 & 2 \\
$D_{\text {cal }}\left(\mathrm{g} \mathrm{cm}^{-3}\right)$ & 1.549 & 1.590 \\
$F(000)$ & 1608 & 1080 \\
$\lambda\left(\mathrm{Mo} \mathrm{K}_{\alpha}\right)(\AA)$ & 0.71069 & 0.71069 \\
$\left.\mu\left(\mathrm{Mo} \mathrm{K}_{\alpha}\right)(\mathrm{mm})^{-1}\right)$ & 1.657 & 6.781 \\
Temperature $(\mathrm{K})$ & 293 & 293 \\
Max $2 \theta\left({ }^{\circ}\right)$ & 55.1 & 55.0 \\
No. reflections measured & 4461 & 11422 \\
No. independent reflections & 4461 & 10933 \\
No. observed reflections & 1824 & 4614 \\
No. parameters & 406 & 514 \\
$R$ & 0.0511 & 0.0670 \\
$w R$ & 0.0315 & 0.0740 \\
$(\Delta / \sigma)_{\text {max }}$ & 0.00 & 0.00 \\
$(\Delta / \rho)_{\text {max }}\left(\mathrm{e} \AA^{-3}\right)$ & 0.00 & 0.00 \\
$(\Delta / \rho)_{\text {min }}\left(\mathrm{e} \AA^{-3}\right)$ & -0.69 & -1.33 \\
\hline & &
\end{tabular}

$\mathrm{Ce}(\text { Clsalen })_{2}$ (1). A solution of cerium(III) chloride heptahydrate $(559 \mathrm{mg}, 1.5 \mathrm{mmol})$ in methanol $\left(20 \mathrm{~cm}^{3}\right)$ was added while being stirred to a hot solution of ligand, $\mathrm{H}_{2}$ Clsalen (843 mg, $2.5 \mathrm{mmol})$, in acetonitrile $\left(150 \mathrm{~cm}^{3}\right)$. A yellow solid of Ce(III)-complex was deposited, after which the complex was gradually oxidized by air, changed to a brownish $\mathrm{Ce}(\mathrm{IV})$ solid, and then dissolved. An ammonia solution $\left(6 \mathrm{~mol} \mathrm{dm}{ }^{-3}, 1 \mathrm{~cm}^{3}\right)$ was added in order to complete the oxidation, and then stirred at $80^{\circ} \mathrm{C}$ for $0.5 \mathrm{~h}$. The reaction mixture was allowed to stand at

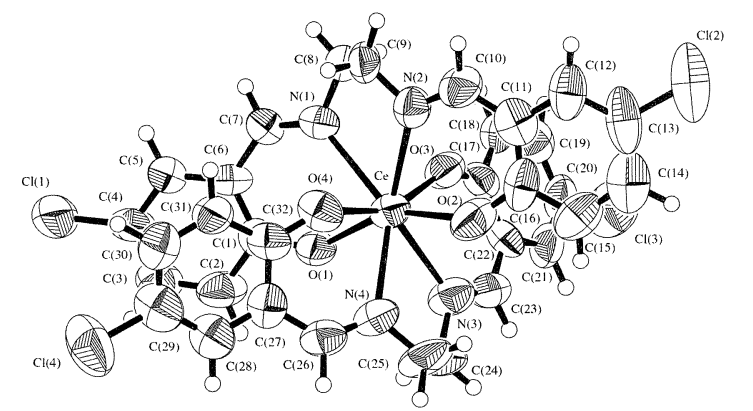

Fig. 2 Molecular structure of $\mathrm{Ce}$ (Clsalen) $)_{2}$ (1) showing the labeling of the non-H atoms. Displacement ellipsoides are drawn at the $50 \%$ probability level.

room temperature for $c a .1$ day to produce dark-brown crystals of (1). Yield: $720 \mathrm{mg}(71.3 \%)$. Anal. Calcd. for $\mathrm{C}_{32} \mathrm{H}_{24} \mathrm{CeCl}_{4} \mathrm{~N}_{4} \mathrm{O}_{4}$ : C, 47.42; H, 2.98; N, 6.91. Found: C, 47.26; $\mathrm{H}, 3.00 ; \mathrm{N}, 7.63 \%$.

$\mathrm{Ce}\left(\mathrm{Br}_{2} \mathrm{Saloph}_{2}\right.$ (2). A dark-brown crystalline product was obtained by using the same procedure as that described for complex 1, except for replacing $\mathrm{H}_{2}$ Clsalen with $\mathrm{H}_{2} \mathrm{Br}_{2}$ Saloph. Yield: $0.85 \%$. Anal. Calcd. for $\mathrm{C}_{40} \mathrm{H}_{20} \mathrm{Br}_{8} \mathrm{CeN}_{4} \mathrm{O}_{4}$ : C, 34.32; $\mathrm{H}$, $1.44 ; \mathrm{N}, 4.00$. Found: $\mathrm{C}, 33.41 ; \mathrm{H}, 1.51 ; \mathrm{N}, 3.54 \%$.

\section{Crystallography}

Each of prismatic dark-brown crystal complexes $\mathbf{1}$ and $\mathbf{2}$ was mounted in a glass fiber. Data were collected on a Rigaku AFC-7R diffractometer. Lorentz and polarization corrections were applied. An absorption correction based on $\Psi$-scans was introduced. The structure was solved by heavy-atom Patterson methods $^{12}$ and expanded using Fourier techniques. ${ }^{13}$ The structure was refined by a full-matrix least-squares procedure on $F$ using the teXsan package. ${ }^{14}$ All non-hydrogen atoms were refined anisotropically. The hydrogen atoms were included with idealized geometry, but not refined. The details of data collection and crystallographic data are summarized in Table 1.

\section{Results and Discussion}

Molecular structure of model complexes

The molecular structure of complex 1, indicating the numbering of the atoms, is shown in Fig. 2. Positional parameters and temperature factors for non- $\mathrm{H}$ atoms are listed in Table 2. The cerium atom is in a distorted square antiprism environment, being bonded to four oxygen atoms and four nitrogen atoms in two quadridentate Clsalen ${ }^{2-}$ dianions, which are oriented perpendicular to each other (meridional type). The meridional structure was also reported for that of [Hpipe][Er$\left.(\text { salen })_{2}\right]($ Hpipe $=$ piperidinium $) .{ }^{15}$ The radius of the tetravalent cerium cation is the smallest in the stable lanthanoides, nearly equal to that of $\mathrm{Lu}^{3+}$. Therefore, the $\mathrm{H}_{2} \mathrm{Nsalen}$ complex with heavy lanthanoid ions seems to have a meridional structure.

A complex of $\mathrm{Ce}^{4+}$ with monochloro- or bromo-substituted $\mathrm{H}_{2}$ saloph, $\left(\mathrm{H}_{2}\right.$ Clsaloph or $\mathrm{H}_{2}$ Brsaloph) was prepared. However, a single crystal suitable for X-ray analysis has not been obtained. Therefore, complexes $\mathrm{Ce}^{4+}$ with dibromo-substituted and non-substituted ligands were used as models.

$\mathrm{X}$-ray analysis of $\mathrm{Ce}(\mathrm{saloph})_{2}$ has been already reported by Terzis et al. ${ }^{11}$ The complex is eight-coordinated by two quadridentate ligands, forming a distorted square antiprism (Fig. 3 ). The two saloph ${ }^{2-}$ ligands are oriented parallel to each other 
Table 2 Positional parameters and $B_{\text {eq }} \mathrm{Ce}(\text { Clsalen })_{2}(\mathbf{1})$

\begin{tabular}{|c|c|c|c|c|}
\hline Atom & $x$ & $y$ & $z$ & $B_{\text {eq }}$ \\
\hline $\mathrm{Ce}$ & $0.17956(4)$ & $0.10542(3)$ & $0.00604(6)$ & $5.92(1)$ \\
\hline $\mathrm{Cl}(1)$ & $-0.2962(2)$ & $0.0535(2)$ & $-0.1360(3)$ & $11.7(1)$ \\
\hline $\mathrm{Cl}(2)$ & $0.5766(3)$ & $0.2636(3)$ & $0.2894(3)$ & $13.6(2)$ \\
\hline $\mathrm{Cl}(3)$ & $0.4304(2)$ & $0.3498(2)$ & $-0.3953(3)$ & $12.0(1)$ \\
\hline $\mathrm{Cl}(4)$ & $-0.1750(2)$ & $-0.1933(2)$ & $0.0261(3)$ & $12.7(1)$ \\
\hline $\mathrm{O}(1)$ & $0.0784(5)$ & $0.0761(5)$ & $-0.1063(5)$ & $6.2(2)$ \\
\hline $\mathrm{O}(2)$ & $0.3071(6)$ & $0.0858(5)$ & $0.0840(6)$ & $8.3(3)$ \\
\hline$O(3)$ & $0.2292(4)$ & $0.2119(4)$ & $-0.0653(5)$ & $6.4(2)$ \\
\hline $\mathrm{O}(4)$ & $0.0983(6)$ & $0.0377(5)$ & $0.1130(6)$ & $7.0(3)$ \\
\hline$N(1)$ & $0.0501(5)$ & $0.2012(5)$ & $0.0302(6)$ & $5.8(3)$ \\
\hline$N(2)$ & $0.1887(7)$ & $0.1958(5)$ & $0.1615(7)$ & $6.4(3)$ \\
\hline$N(3)$ & $0.2787(7)$ & $0.0630(6)$ & $-0.1430(8)$ & $7.4(4)$ \\
\hline$N(4)$ & $0.2001(6)$ & $-0.0434(5)$ & $-0.0191(8)$ & $7.2(3)$ \\
\hline$C(1)$ & $-0.0059(8)$ & $0.0757(7)$ & $-0.1127(8)$ & $5.6(3)$ \\
\hline$C(2)$ & $-0.043(1)$ & $0.0155(9)$ & $-0.1739(9)$ & $8.1(5)$ \\
\hline$C(3)$ & $-0.1327(9)$ & $0.0107(8)$ & $-0.177(1)$ & $8.9(5)$ \\
\hline$C(4)$ & $-0.1867(9)$ & $0.0638(7)$ & $-0.1320(9)$ & $7.6(4)$ \\
\hline$C(5)$ & $-0.1511(7)$ & $0.1232(6)$ & $-0.0758(7)$ & $5.2(3)$ \\
\hline$C(6)$ & $-0.0616(8)$ & $0.1311(6)$ & $-0.0651(7)$ & $5.5(3)$ \\
\hline$C(7)$ & $-0.0269(6)$ & $0.1926(5)$ & $-0.0028(9)$ & $5.0(2)$ \\
\hline$C(8)$ & $0.0675(7)$ & $0.2667(7)$ & $0.0961(9)$ & $6.6(4)$ \\
\hline $\mathrm{C}(9)$ & $0.1086(8)$ & $0.2347(8)$ & $0.1890(9)$ & $7.0(4)$ \\
\hline$C(10)$ & $0.253(1)$ & $0.2190(9)$ & $0.212(1)$ & $7.3(5)$ \\
\hline$C(11)$ & $0.341(1)$ & $0.193(1)$ & $0.194(1)$ & $7.2(5)$ \\
\hline$C(12)$ & $0.407(1)$ & $0.230(1)$ & $0.247(1)$ & $8.3(5)$ \\
\hline$C(13)$ & $0.493(1)$ & $0.214(1)$ & $0.229(1)$ & $9.7(6)$ \\
\hline$C(14)$ & $0.516(1)$ & $0.153(1)$ & $0.166(1)$ & $9.5(6)$ \\
\hline$C(15)$ & $0.454(1)$ & $0.1093(8)$ & $0.1153(9)$ & $8.6(5)$ \\
\hline$C(16)$ & $0.3657(9)$ & $0.1303(9)$ & $0.132(1)$ & $6.9(5)$ \\
\hline$C(17)$ & $0.2726(8)$ & $0.2416(7)$ & $-0.142(1)$ & $5.8(4)$ \\
\hline$C(18)$ & $0.2725(6)$ & $0.3232(8)$ & $-0.1627(9)$ & $6.2(4)$ \\
\hline$C(19)$ & $0.3185(9)$ & $0.3572(6)$ & $-0.2394(9)$ & $6.9(4)$ \\
\hline $\mathrm{C}(20)$ & $0.3680(8)$ & $0.3072(8)$ & $-0.299(1)$ & $7.3(4)$ \\
\hline$C(21)$ & $0.3702(8)$ & $0.2276(9$ & $-0.2833(9)$ & $7.0(4)$ \\
\hline $\mathrm{C}(22)$ & $0.320(1)$ & $0.1928(8)$ & $-0.2066(8)$ & $5.9(4)$ \\
\hline $\mathrm{C}(23)$ & $0.3211(9)$ & $0.1096(8)$ & $-0.2022(8)$ & $6.9(3)$ \\
\hline$C(24)$ & $0.2837(9)$ & $-0.0224(7)$ & $-0.1626(9)$ & $9.2(5)$ \\
\hline$C(25)$ & $0.2778(8)$ & $-0.0669(6)$ & $-0.067(1)$ & $9.3(4)$ \\
\hline$C(26)$ & $0.1381(8)$ & $-0.0952(6)$ & $-0.007(1)$ & $6.9(3)$ \\
\hline $\mathrm{C}(27)$ & $0.0529(8)$ & $-0.0825(7)$ & $0.0331(9)$ & $6.6(4)$ \\
\hline$C(28)$ & $-0.0123(9)$ & $-0.1374(7)$ & $0.0152(9)$ & $7.3(4)$ \\
\hline$C(29)$ & $-0.0921(9)$ & $-0.1280(8)$ & $0.0533(9)$ & $8.4(5)$ \\
\hline$C(30)$ & $-0.1089(9)$ & $-0.0635(9)$ & $0.113(1)$ & $8.3(5)$ \\
\hline$C(31)$ & $-0.045(1)$ & $-0.0110(8)$ & $0.1356(9)$ & $7.0(4)$ \\
\hline C(32) & $0.0377(9)$ & $-0.0153(7)$ & $0.0964(9)$ & $5.8(4)$ \\
\hline
\end{tabular}

$B_{\text {eq }}=(8 / 3) \pi^{2}\left(U_{11}\left(a a^{*}\right)^{2}+U_{22}\left(b b^{*}\right)^{2}+U_{33}\left(c c^{*}\right)^{2}+2 U_{12}\left(a a^{*} b b^{*}\right) \cos \gamma+\right.$ $2 U_{13}\left(a a^{*} c c^{*}\right) \cos \beta+2 U_{23}\left(b b^{*} c c^{*}\right) \cos \alpha$.

(sandwich type). A 1:2 complex with $\mathrm{Ln}$ and a planar quadridentate ligand, such as $\mathrm{H}_{2} \mathrm{saloph}$, seems to prefer a sandwich orientation rather than a meridional one, because of the rigidity of the phenylenediamine bridge in the ligand.

The molecular structure of complex 2, indicating the numbering of the atoms, is shown in Fig. 4. The positional parameters and temperature factors for non- $\mathrm{H}$ atoms are listed in Table 3. The cerium atom is in a distorted square antiprism environment, belonging to two largely distorted $\mathrm{Br}_{2} \mathrm{Saloph}^{2-}$, which are oriented in a meridional structure in a similar manner as complex 1 (Fig. 5). The dihedral angles between two cerium coordination least-squares planes $(\mathrm{Ce}-\mathrm{O}(1)-\mathrm{N}(1)-\mathrm{N}(2)-\mathrm{O}(2)$ and $\mathrm{Ce}-\mathrm{O}(3)-\mathrm{N}(3)-\mathrm{N}(4)-\mathrm{O}(4))$ in complex $\mathbf{1}$ and complex 2 are $92.64^{\circ}$ and $92.40^{\circ}$, respectively. Here, the ideal dihedral angles between their planes in the meridional type and the sandwich type are $90^{\circ}$ and $0^{\circ}$, respectively. The conformation of $\mathrm{Br}_{2} \mathrm{Saloph}^{2-}$ in the complex differs from that of $\mathrm{Ce}$ (saloph $)_{2}$,

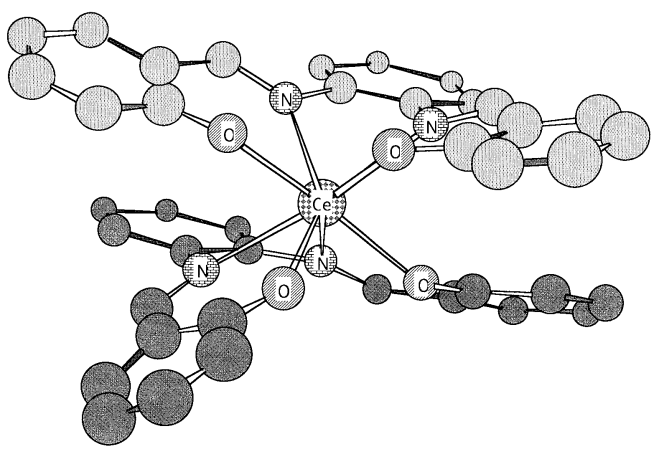

Fig. 3 Molecular structure of Ce(saloph) $)_{2}$.

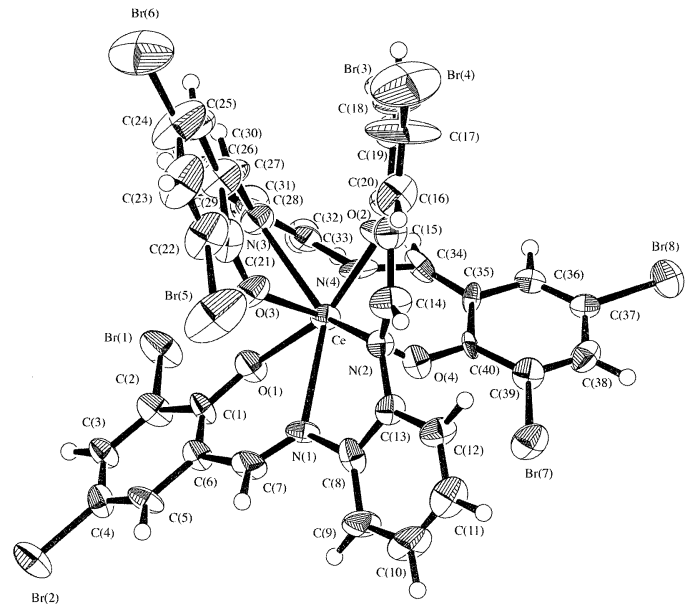

Fig. 4 Molecular structure of $\mathrm{Ce}\left(\mathrm{Br}_{2} \mathrm{Saloph}\right)_{2}$ (2) showing the labeling of the non-H atoms. Displacement ellipsoides are drawn at the $50 \%$ probability level.

against our expectation. A steric repulsion between $\mathrm{Br}$ atoms at the 3-position of salicylidene groups in the two ligands appears to cause the meridional orientation. In the conformation of $\mathrm{Ce}\left(\mathrm{Br}_{2} \mathrm{saloph}\right)_{2}$, assuming the same sandwich orientation as that of $\mathrm{Ce}(\mathrm{saloph})_{2}$, the interatomic distance between $\operatorname{Br}(1)$ and $\operatorname{Br}(5)$ (or $\operatorname{Br}(7)$ ) should be shorter than the van der Waals distance. $\mathrm{H}_{2} \mathrm{Nsaloph}$ is a mono-substituted molecule for $\mathrm{H}_{2} \mathrm{saloph}$, at the 5-position of salicylidene group, and the substituent cannot cause a steric repulsion between the two ligands in the complex. Therefore, the complex with the heavy lanthanoids seems not to be a meridional structure but a sandwich one.

From the result of the comparison between the molecular structures of $\mathrm{Ce}(\mathrm{Clsalen})_{2}$ and $\mathrm{Ce}(\text { saloph })_{2}$, we consider that the difference in the mutual separability of the small $\mathrm{Ln}^{3+}\left(\mathrm{Lu}^{3+}\right.$, $\mathrm{Yb}^{3+}, \mathrm{Tm}^{3+}$, etc.) in the $\mathrm{H}_{2} \mathrm{Nsalen}-\mathrm{KCl}$ and $\mathrm{H}_{2} \mathrm{Nsaloph}-\mathrm{KCl}$ extraction systems results from the orientation of two coordinating ligands. Namely, the formation of a meridional structure as extracted species can give a higher separability than that of the sandwich structure. Here, the superiority of the ligands which can form the meridional complexes seems to be observed not only in small (heavy) lanthanoid ions, but also in large (light) lanthanoid ions. In the meridional complexes, a larger ion obviously causes a larger distortion of the ligand molecules and, namely, a lower stability constant and extraction constant. 
Table 3 Positional parameters and $B_{\text {eq }} \mathrm{Ce}\left(\mathrm{Br}_{2} \mathrm{saloph}\right)_{2}(\mathbf{2})$

\begin{tabular}{|c|c|c|c|c|}
\hline Atom & $x$ & $y$ & $z$ & $B_{\text {eq }}$ \\
\hline $\mathrm{Ce}$ & $0.69472(5)$ & $0.25106(5)$ & $0.83175(6)$ & $2.48(2)$ \\
\hline $\operatorname{Br}(1)$ & $0.7263(1)$ & $0.3978(1)$ & $0.5110(1)$ & $5.01(4)$ \\
\hline $\operatorname{Br}(2)$ & $1.1611(1)$ & $0.43540(9)$ & $0.6275(1)$ & $4.45(4)$ \\
\hline $\operatorname{Br}(3)$ & $0.4127(1)$ & $0.0539(1)$ & $0.7301(1)$ & $8.24(6)$ \\
\hline $\operatorname{Br}(4)$ & $0.6377(2)$ & $-0.2065(1)$ & $0.9608(2)$ & $11.08(8)$ \\
\hline $\operatorname{Br}(5)$ & $0.9799(1)$ & $0.0195(1)$ & $0.8603(2)$ & $9.62(6)$ \\
\hline $\operatorname{Br}(6)$ & $0.7752(2$ & $-0.2281(1)$ & $0.5280(2)$ & $9.73(7)$ \\
\hline $\operatorname{Br}(7)$ & $0.6449(1)$ & $0.40626(9)$ & $1.2127(1)$ & $4.30(4)$ \\
\hline $\operatorname{Br}(8)$ & $0.2013(1)$ & $0.4632(1)$ & $1.1048(1)$ & $5.58(5)$ \\
\hline $\mathrm{O}(1)$ & $0.7614(6)$ & $0.3302(5)$ & $0.7328(6)$ & $3.5(2)$ \\
\hline $\mathrm{O}(2)$ & $0.5902(6)$ & $0.1582(5)$ & $0.8584(6)$ & $3.9(2)$ \\
\hline $\mathrm{O}(3)$ & $0.7984(6)$ & $0.1409(6)$ & $0.7720(6)$ & $3.9(2)$ \\
\hline$O(4)$ & $0.6253(5)$ & $0.3500(5)$ & $0.9597(6)$ & $3.0(2)$ \\
\hline $\mathrm{N}(1)$ & $0.8734(7)$ & $0.3022(6)$ & $0.9420(8)$ & $2.7(2)$ \\
\hline$N(2)$ & $0.7692(7)$ & $0.1851(6)$ & $1.0149(7)$ & $2.4(2)$ \\
\hline $\mathrm{N}(3)$ & $0.6209(7)$ & $0.1844(7)$ & $0.6241(8)$ & $3.4(3)$ \\
\hline $\mathrm{N}(4)$ & $0.5161(7)$ & $0.3233(5)$ & $0.7410(7)$ & $2.7(2)$ \\
\hline$C(1)$ & $0.8509(8)$ & $0.3513(7)$ & $0.7110(9)$ & $2.6(3)$ \\
\hline $\mathrm{C}(2)$ & $0.8543(9)$ & $0.3850(8)$ & $0.612(1)$ & $3.3(3)$ \\
\hline $\mathrm{C}(3)$ & $0.9453(9)$ & $0.4082(7)$ & $0.5853(9)$ & $3.0(3)$ \\
\hline$C(4)$ & $1.0396(8)$ & $0.4020(8)$ & $0.6632(9)$ & $3.0(3)$ \\
\hline $\mathrm{C}(5)$ & $1.0386(8)$ & $0.3689(8)$ & $0.758(1)$ & $3.3(3)$ \\
\hline$C(6)$ & $0.9464(8)$ & $0.3443(8)$ & $0.7852(9)$ & $2.8(3)$ \\
\hline$C(7)$ & $0.9499(9)$ & $0.3232(8)$ & $0.897(1)$ & $3.6(3)$ \\
\hline $\mathrm{C}(8)$ & $0.8912(8)$ & $0.2954(8)$ & $1.063(1)$ & $3.1(3)$ \\
\hline $\mathrm{C}(9)$ & $0.957(1)$ & $0.3499(8)$ & $1.139(1)$ & $4.0(4)$ \\
\hline$C(10)$ & $0.970(1)$ & $0.340(1)$ & $1.251(1)$ & $5.3(4)$ \\
\hline$C(11$ & $0.916(1)$ & $0.2807(9)$ & $1.287(1)$ & $4.5(4)$ \\
\hline$C(12)$ & $0.853(1)$ & $0.2282(8)$ & $1.210(1)$ & $3.5(3)$ \\
\hline$C(13)$ & $0.8375(9)$ & $0.2349(8)$ & $1.0959(9)$ & $2.7(3)$ \\
\hline$C(14)$ & $0.758(1)$ & $0.1078(9)$ & $1.029(1)$ & $4.2(4)$ \\
\hline$C(15)$ & $0.683(1)$ & $0.0485(9)$ & $0.963(1)$ & $3.7(4)$ \\
\hline$C(16)$ & $0.691(1)$ & $-0.0378(9)$ & $0.986(1)$ & $4.9(4)$ \\
\hline$C(17)$ & $0.621(2)$ & $-0.093(1)$ & $0.937(2)$ & $9.9(7)$ \\
\hline $\mathrm{C}(18)$ & $0.541(2)$ & $-0.069(1)$ & $0.857(1)$ & $7.8(6)$ \\
\hline$C(19)$ & $0.529(1)$ & $0.012(1)$ & $0.835(1)$ & $5.3(4)$ \\
\hline$C(20)$ & $0.599(1)$ & $0.0821(9)$ & $0.884(1)$ & $4.6(4)$ \\
\hline$C(21)$ & $0.794(1)$ & $0.062(1)$ & $0.719(1)$ & $4.5(4)$ \\
\hline $\mathrm{C}(22)$ & $0.867(1)$ & $-0.012(1)$ & $0.741(1)$ & $6.0(5)$ \\
\hline$C(23)$ & $0.862(1)$ & $-0.096(1)$ & $0.687(1)$ & $6.8(5)$ \\
\hline$C(24)$ & $0.777(1)$ & $-0.114(1)$ & $0.606(1)$ & $7.9(5)$ \\
\hline$C(25)$ & $0.706(1)$ & $-0.0508(9)$ & $0.576(1)$ & $4.8(4)$ \\
\hline$C(26)$ & $0.708(1)$ & $0.0357(8)$ & $0.629(1)$ & $4.1(4)$ \\
\hline $\mathrm{C}(27)$ & $0.6335(9)$ & $0.0998(9)$ & $0.583(1)$ & $3.8(3)$ \\
\hline$C(28)$ & $0.5544(8)$ & $0.2417(8)$ & $0.558(1)$ & $3.1(3)$ \\
\hline$C(29)$ & $0.541(1)$ & $0.2327(9)$ & $0.437(1)$ & $4.1(4)$ \\
\hline $\mathrm{C}(30)$ & $0.481(1)$ & $0.2915(9)$ & $0.379(1)$ & $4.5(4)$ \\
\hline $\mathrm{C}(31)$ & $0.433(1)$ & $0.363(1)$ & $0.437(1)$ & $4.7(4)$ \\
\hline $\mathrm{C}(32)$ & $0.4446(9)$ & $0.3756(8)$ & $0.558(1)$ & $3.5(3)$ \\
\hline$C(33)$ & $0.5047(8)$ & $0.3139(8)$ & $0.619(1)$ & $3.0(3)$ \\
\hline $\mathrm{C}(34)$ & $0.4373(8)$ & $0.3593(7)$ & $0.799(1)$ & $2.8(3)$ \\
\hline $\mathrm{C}(35)$ & $0.4424(9)$ & $0.3802(7)$ & $0.9116(8)$ & $2.0(3)$ \\
\hline $\mathrm{C}(36)$ & $0.3463(9)$ & $0.4089(7)$ & $0.948(1)$ & $2.5(3)$ \\
\hline $\mathrm{C}(37)$ & $0.3355(9)$ & $0.4315(7)$ & $1.053(1)$ & $2.8(3)$ \\
\hline $\mathrm{C}(38)$ & $0.428(1)$ & $0.4320(7)$ & $1.136(1)$ & $3.4(3)$ \\
\hline $\mathrm{C}(39)$ & $0.5209(9)$ & $0.4070(8)$ & $1.099(1)$ & $3.3(3)$ \\
\hline $\mathrm{C}(40)$ & $0.5341(9)$ & $0.3770(7)$ & $0.9901(9)$ & $2.3(3)$ \\
\hline
\end{tabular}

$B_{\text {eq }}=(8 / 3) \pi^{2}\left(U_{11}\left(a a^{*}\right)^{2}+U_{22}\left(b b^{*}\right)^{2}+U_{33}\left(c c^{*}\right)^{2}+2 U_{12}\left(a a^{*} b b^{*}\right) \cos \gamma+\right.$ $2 U_{13}\left(a a^{*} c c^{*}\right) \cos \beta+2 U_{23}\left(b b^{*} c c^{*}\right) \cos \alpha$.

View of the design of the superior mutual separation reagent As mentioned above, the formation of a lanthanoid complex having a meridional structure is greatly affected by its ion size and, therefore, $\mathrm{H}_{2} \mathrm{Nsalen}$ seems to show a high mutual extraction selectivity of lanthanoids. From this reason, the cavity (the space in which metal ion can be fitted with the ligand) in the meridional structure may be preferable for recognizing the ion size. The efficient separation of a specific size of lanthanoids can be realized by varying the cavity size in the $\mathrm{H}_{2} \mathrm{X}$ salen type ligands.

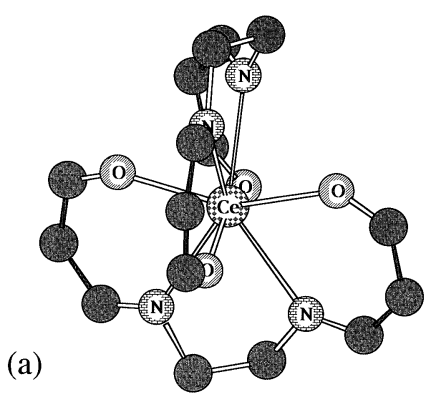

(b)

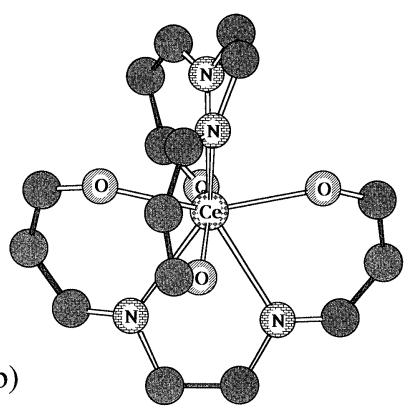

Fig. 5 Coordination geometry about the $\mathrm{Ce}$ atom in a meridionaltype complex showing the atom labeling scheme: (a) $\mathrm{Ce}(\text { Clsalen })_{2}$ (1); (b) $\mathrm{Ce}\left(\mathrm{Br}_{2} \text { saloph }\right)_{2}$ (2).

On the other hand, $\mathrm{H}_{2} \mathrm{Br}_{2}$ saloph can also form meridional type complexes with heavy lanthanoid ions because of a steric repulsion between $\mathrm{Br}$ atoms at the 3-position of the salicylidene groups. This fact suggests that, in forming Ln complexes with the $\mathrm{H}_{2}$ saloph type ligands, the substituent at the 3-position of salicylidene groups can affect the conformation of the ligand. The introduction of various substituents at the 3-position of the salicylidene groups in those ligands may give a novel mutual separation ability of lanthanoids.

The separation systems discussed here are based on "structural control on the orientation of the ligand" in the extracted complex according to ion size, and the mutual separability of $\mathrm{Ln}^{3+}$ can be extremely improved in this extraction system. The separation in a new category system must be interesting and will be useful in the future.

Single-crystal X-ray diffraction is an effective method for the design of analytical reagents, though there is a restriction in that only crystalline samples can be used.

\section{Supplementary Material}

The detailed crystallographic data of the structure described in this paper are available from the authors.

\section{Acknowledgements}

This work was financially supported by Sasakawa Scientific Research Grants (No. 10-148 and No. 11-137K) from the Japan Science Society. 


\section{References}

1. G. Adachi, "Kidorui-no Kagaku (Science of Rare Metal, in Japanese)", 1999, Kagakudojin.

2. R. D. Shannon and C. T. Prewitt, Acta Crystallogr., 1969 B25, 925 .

3. R. D. Shannon and C. T. Prewitt, Acta Crystallogr., 1970, B26, 1046.

4. R. D. Shannon, Acta Crystallogr., 1976, A32, 751.

5. T. Sekine and Y. Hasegawa, "Solvent Extraction in Chemistry", 1977, Dekker, New York.

6. S. Alegret, "Developments in Solvent Extraction", 1988, Wiley, New York.

7. T. Takayanagi and T. Yotsuyanagi, Bull. Chem. Soc. Jpn., 1994, 67, 1835.

8. S. Motomizu and H. Freiser, Solv. Extr. Ion Exch., 1985, 3 , 637

9. N. Hirayama, I. Takeuchi, T. Honjo, K. Kubono, and H.
Kokusen, Anal. Chem., 1997, 69, 4814.

10. H. Diehl and C. C. Hach, Inorg. Synth., 1950, 3, 196.

11. A. Terzis, D. Mentzafos, and H. A. Tajmir-Riahi, Inorg. Chim. Acta, 1984, 84, 187.

12. P. T. Beurskens, G. Admiraal, G. Beurskens, W. P. Bosman, S. Garcia-Granda, R. O. Gould, J. M. M. Smith, and C. Smykalla, PATTY: The DIRDIF Program System, Technical Report of the Crystallography Laboratory, 1992, University of Nijmegen, The Netherlands.

13. P. T. Beurskens, G. Admiraal, G. Beurskens, W. P. Bosman, R. DecGelder, R. Israel, and J. M. M. Smith, DIRDIF-94: The DIRDIF-94 Program System, Technical Report of the Crystallography Laboratory, 1994, University of Nijmegen, The Netherlands.

14. teXsan for Windows: Crystal Structure Analysis Package, 1998, Molecular Structure Corporation, The Woodland, TX77381, USA.

15. S. Mangani, A. Takeuchi, S. Yamada, and P. Orioli, Inorg. Chim. Acta, 1989, 155, 149. 